https://doi.org/10.46344/JBINO.2021.v10i02.23

\title{
INCREASED PLASMA TRANSFORMING GROWTH FACTOR BETA1 IMPEDES OCULAR PERFUSION PRESSURE AND WORSEN GLAUCOMA IN-PATIENT ATTENDING GLAUCOMA CLINIC AT MAKKAH SPECIALIST EYE HOSPITAL, KANO, KANO STATE, NIGERIA
}

\author{
Hassan, S. ${ }^{1}$, Okoyeocha, J.O. ${ }^{2}$, Mohammed, I.Y. ${ }^{4}$, Elkhashab, M.M. ${ }^{3}$ and Salisu, A.I. ${ }^{3}$ \\ 1. Department of Ophthalmology, College of Health Sciences, Bayero University Kano, Kano State/Aminu Kano Teaching Hospital, \\ Kano, Kano State, Nigeria. \\ Email: Sadiah@yahoo.com \\ 2. Department of Ophthalmology, Usmanu Danfodiyo University Teaching Hospital Sokoto, Sokoto State, Nigeria. E-mail: \\ 3. Department of Human Physiology, Faculty of Basic Medical Sciences, College of Health Sciences, Bayero University Kano, Kano State, \\ Nigeria. \\ 4. Department of Chemical Pathology, College of Health Sciences Bayero University Kano, Kano State/Aminu Kano Teaching Hospital, \\ Kano, Kano State, Nigeria. \\ (Received on Date: 30 December 2020 \\ Date of Acceptance: 16 February 2021 \\ Date of Publish: 19 March 2021)
}

\section{ABSTRACT}

This research investigated a relationship between plasma TGF- $\beta 1$ and POAG among 96 participants comprising 60 glaucoma cases that served as study group and 38 apparently normal individuals that served as control group. The clinical parameters extracted from the subjects' files were intraocular pressure (IOP) and cup-disc (C/D) ratio, while Age and BP were directly obtained from subjects. Blood samples were obtained from the subjects, and subjected to chemical analysis using sandwich enzyme linked immunosorbent assay (sELISA) to assess the plasma concentration of transforming growth factor betal (TGF- $\beta 1$ ) and thrombospondin-1 (TSP-1) levels. The mean arterial pressure (MAP) and mean ocular perfusion pressure (MOPP) were calculated. Data were analysed using Mann-Whitney test and Spearman's ranking methods. The plasma TGF- $\beta 1$ level in glaucoma subjects was significantly higher than normal controls $(P=0.040)$ and a significant $(P=0.009)$ decreased value of MOPP in glaucoma subjects than the controls. Furthermore, this study found significant positive association between TGF- $\beta 1$ versus MAP $(P=0.000)$ and MOPP $(P=0.004)$ among subjects with $P O A G$ and significant positive association between TGF- $\beta 1$ versus Age $(P=0.033)$, MAP $(P=0.006)$ and MOPP $(P=0.024)$ among non-glaucoma subjects. The rise in plasma TGF- $\beta 1$ together with a fall in MOPP values are believed to lead to deterioration of the optic nerve head which eventually leads to optic nerve atrophy. Therefore, there is a possibility for the use of plasma TGF- $\beta 1$ as a biomarker to monitor the progression of glaucoma disease and MOPP should be evaluated in glaucoma patients.

Keywords: Transforming Growth Factor -Beta1, Ocular Perfusion Pressure, Kano, Nigeria 2021 March Edition | www.jbino.com | Innovative Association 


\section{INTRODUCTION}

Glaucoma is defined as a group of disorders characterized by a progressive optic neuropathy resulting in a characteristic appearance of the optic disc and a specific pattern of irreversible visual field defects that are associated with frequently but not without raised IOP (Khurana (2007). So emphasis has shifted from elevated intraocular pressure as the only damaging factor in glaucoma to it being one of the factors in the glaucoma damage in which retinal ganglion cells (RGCS) apoptosis occurs. Agarwal et al., (2009) reported that apoptosis is the primary and early cause of RGCs death in glaucoma, then necrosis occurs in the late stage of the disease process. Primary factors of glaucoma toxicity are based on two theories; mechanical theory resulting from elevated IOP and vascular insufficiency theory resulting from the decreased ocular perfusion pressure. The secondary factors include toxic effects of glutamate, oxygen free radicals and nitric oxides released during RGCs apoptosis due to primary insults (Hendrick et al., 1994; Chauhan, 1995). Frequently, glaucoma is associated with a higher than normal pressure inside the eyeball (Coleman, 1999; Henson et al., 2000). It has been reported that mean $1 O P>25.75 \mathrm{mmHg}$ had $13 \%$ risk of developing glaucoma. However, mean IOP $>23.75$ but IOP $\leq 25.75 \mathrm{mmHg}$ had $10 \%$ risk of developing glaucoma, while mean IOP $<23.75 \mathrm{mmHg}$ had $9 \%$ risk of developing glaucoma in individuals with normal central corneal thickness between $555 \mu \mathrm{m}$ to 588um (Kanski, 2016). Glaucomatous changes have been observed in individuals with normal IOP, Chauhan (1995) suggesting a critical role of other factors in the initiation and progression of glaucomatous changes. Studies have shown an association between vascular insufficiency and glaucoma; diastolic ocular perfusion pressure (DOPP) $\leq 40 \mathrm{mmHg}$ or mean ocular perfusion pressure (MOPP) $\leq 50 \mathrm{mmHg}$ was found to be associated with 1.9 and 3.6 times increase in POAG respectively (Memarzadeh et al., 2010).

Other risk factors of developing glaucoma in healthy subjects include black race, old age (above 40years), the peculiar larger optic disc structure of black people, a positive family history, and vascular factors such as systemic hypertension, perfusion pressure, vasospasm, atherosclerosis and acute hypotension, so also diabetes, myopia, a history of typical migraine headaches, and thinner central corneal (Omoti \& Edema, 2007; Wolfs et al., 1998). Current screening techniques have poor sensitivity and are unable to diagnose early POAG; if elevated intraocular pressure (IOP) is used to screen for POAG, more than $50 \%$ of POAG patients have an IOP that is $<21 \mathrm{mmHg}$ (Sommer, et al., 1991). Also, screening using automated perimetry for glaucomatous visual field defects lacks the resolution to detect early 
POAG, as $>35 \%$ of the retinal ganglion cells can be lost before any visual field defects is observed (Kerrigan-Baumrind et al., 2000). Optical imaging methods do not provide information of the acute molecular processes leading deformations within the optic nerve head (ONH) tissues (Sigal et al., 2009). Over half of individuals with POAG are undiagnosed or untreated (Shaikh, YU, \& Coleman, 2014). Vision loss from glaucoma is silent, slow, progressive, irreversible, and preventable (Robert, 2008).

Transforming growth factor beta isoforms, TGF- $\beta 1,-\beta 2$, and $-\beta 3$, are small $(25 \mathrm{kDa})$ secreted dimeric signaling proteins (multifunctional polypeptides) that regulate many essential cellular processes in many parts of the body; liver, lungs, skin including eye structures (Huang, Schor, \& Hinck, 2014; Tandon, Torey, Shama, Gupta, \& Mohan, 2010).

Transforming growth factor betal (TGF- $\beta 1$ ) can serve as a nutrition factor and antiapoptotic factor; offering a self-protection mechanism for apoptosis of RGCs (Tao et al., 2011). The gradual morphogenesis leading to apoptosis can allow for neuroprotective intervention of TGF- $\beta 1$ and hence salvage the RGCs. Changes in TGF$\beta 1$ secretion within the eye might be detectable as changes in the plasma concentration of TGF- $\beta 1$ just as in the aqueous humor (AH) of glaucoma patients (Kuchtey and Kuchtey, 2014). But increased TGF- $\beta 1$ concentration causes chemotaxis of pro-inflammatory cells such as monocytes, lymphocytes, neutrophils. Also, it causes fibroblasts and vascular growth factors production, ECM remodeling and angiogenesis (Padua \& Massaque, 2009). The initiation of fibroblast proliferation process leads to cascade of events that leads to collagen production, amplification and decreased ECM degradation, resulting to scar formation in Trabecular meshwork (Liu, Wan, \& Cao, 2004). Previous studies (Kuchtey et al., 2014) did not consider the consequences of increased blood TGF- $\beta 1$ concentration on the vessels. Therefore, assessment of plasma TGF- $\beta 1$ and its relation to ocular perfusion and POAG will aid in monitoring the progression of glaucoma disease.

\section{METHODOLOGY}

The study was conducted at Makkah Specialist Eye Hospital located in Kano metropolis, Kano state. It was a cross sectional study of individuals attending glaucoma out patients clinic. Using systematic random sampling method, 96 subjects were recruited; comprising of 60 glaucoma patients serving as subjects and 38 age-matched controls. Ethical approval was obtained from the Kano State Hospital Management Board. Participants were requested to sign the informed consent form before commencement of research after thorough explanation of the research purpose and procedures to them. The study was in line with the rules and regulations of the declaration of Helsinki 
1964 as amended (World Medical Association, Brazil, 2013). After subjects signed the informed consent form, the clinical parameters extracted from the subjects files were IOP, C/D ratio, while information about age and $B P$ measurement were directly obtained from the cohorts. The demographic data including family history were obtained from subjects directly using data captured questionnaire. Individuals were diagnosed as glaucomatous by the fellowship trained ophthalmologist treating them; if they had cup-disc ratio (CDR) $\geq 0.60,10 P>21 \mathrm{mmHg}$ and visual field defects while those with CDR $<0.6,1 O P \leq 21.0 \mathrm{mmHg}$ and no visual field defect were regarded as nonglaucomatous. Blood samples were obtained from the subjects, then subjected to chemical analysis by sELISA and plasma concentration of TGF- $\beta 1$ and TSP-1 determined.

The MOPP in all subjects were determined using the formulae below (Van Keer et al., 2016):

$$
M O P P=\frac{2(M A P)}{3}-1 O P
$$

Data were presented as median (range) and analyzed using SPSS 21.0 (SPSS Inc, Chicago, IL). Median samples were compared using Mann-Whitney test. Probability value was set at $\mathrm{P}=0.05(\mathrm{P}<0.05$ was considered significant). The association between TGF- $\beta 1$, and other ocular physiologic parameters in the two groups were tested using Spearman's correlation coefficient. 


\section{RESULTS}

Table 1: Distribution of Socio-demographic Characteristics of POAG and Non-glaucoma Subjects

\begin{tabular}{|c|c|c|c|}
\hline Variables & $\begin{array}{l}\text { POAG } \\
(\mathrm{n}=60), \mathrm{n}(\%)\end{array}$ & $\begin{array}{l}\text { Non-glaucoma } \\
\text { Total }(\mathrm{n}=36), \mathrm{n}(\%)\end{array}$ & P-value \\
\hline \multicolumn{4}{|l|}{ Age group (years) } \\
\hline 40-49 & $12(20.0)$ & $9(25.5)$ & \multirow{4}{*}{0.715} \\
\hline $50-59$ & $16(26.7)$ & $6(16.7)$ & \\
\hline $60-69$ & $21(35.0)$ & $12(33.3)$ & \\
\hline 70 and above & $11(18.3)$ & $9(25.0)$ & \\
\hline \multicolumn{4}{|l|}{ Sex } \\
\hline Male & $30(50.0)$ & $18(50.0)$ & \multirow[t]{2}{*}{1.000} \\
\hline Female & $30(50.0)$ & $18(50.0)$ & \\
\hline \multicolumn{4}{|l|}{ Residence } \\
\hline Urban & $29(48.3)$ & $15(41.7)$ & \multirow{3}{*}{0.503} \\
\hline Rural & $23(38.3)$ & $15(41.7)$ & \\
\hline Semi-urban & $8(13.3)$ & $6(16.6)$ & \\
\hline \multicolumn{4}{|l|}{ Education } \\
\hline Informal & $15(25.0)$ & $8(22.2)$ & \multirow{4}{*}{0.735} \\
\hline Primary $\left(1^{0}\right)$ & $8(13.3)$ & $7(19.4)$ & \\
\hline Secondary $\left(2^{0}\right)$ & $15(25.0)$ & $10(27.8)$ & \\
\hline Tertiary $\left(3^{0}\right)$ & $22(36.7)$ & $11(30.6)$ & \\
\hline \multicolumn{4}{|l|}{ Occupation } \\
\hline Workers (Private \& Public) & $18(30.0)$ & $10(27.8)$ & \multirow{5}{*}{0.750} \\
\hline Petty Traders & $7(11.7)$ & $8(22.2)$ & \\
\hline Retirees & $11(18.3)$ & $2(5.6)$ & \\
\hline House Wives & $13(21.7)$ & $13(36.1)$ & \\
\hline Farmers & $11(18.3)$ & $3(8.3)$ & \\
\hline \multicolumn{4}{|l|}{ Monthly Income } \\
\hline Below N5,000 & $4(6.7)$ & $4(11.1)$ & \multirow{6}{*}{0.767} \\
\hline N5,000-N9,900 & $20(33.3)$ & $11(30.6)$ & \\
\hline $\mathrm{N} 10,000-\mathrm{N} 49,900$ & $22(36.7)$ & $12(33.3)$ & \\
\hline N50,000-N99,900 & $6(10.0)$ & $6(16.7)$ & \\
\hline $\mathrm{N} 100,000-\mathrm{N} 200,000$ & $7(11.7)$ & $3(8.3)$ & \\
\hline Above N200,000 & $1(1.7)$ & & \\
\hline \multicolumn{4}{|c|}{ Family History of Glaucoma } \\
\hline Positive (+) & $55(91.7)$ & $5(13.9)$ & \multirow[t]{2}{*}{$0.000 *$} \\
\hline Negative (-) & $5(8.3 \%)$ & $31(86.1)$ & \\
\hline
\end{tabular}

* Statistical significance at $\mathrm{p}<0.05$ 
The distribution of socio-demographic characteristics of the participants is shown in table 1 above, subjects comprised of 48 (50.0\%) males and 48 (50.0\%) females giving a total of 96 participants. Of these were 30 males (50.0\%) and 30 females $(50.0 \%)$ in POAG subjects while in the nonglaucoma there were 18 males $(50.0 \%)$ and 18 females $(50.0 \%)$ and there was no significant difference in the sex between the two groups $(P=1.000)$. Large number of participants were in 60-69 age bracket in POAG subjects $(n=21 ; 35.0 \%)$ and in nonglaucoma subjects $(n=12 ; 33.3 \%)$ and there was no significant difference in the age of participants between the study and controls $(P=0.715)$. Likewise, there were no significant difference $(P<0.05)$ in most of the socio-demographic characteristics (regarding the area of residence, education, job or income) of the participants between POAG subjects and non-glaucoma subjects. However, family history of participants was shown that most of the POAG subjects ( $n=55,91.7 \%)$ had positive family history of glaucoma while most of non-glaucoma subjects $(n=31$, $86.1 \%$ ) had negative family history of glaucoma. Positive family history of glaucoma is defined as those that had at least one family member (sibling, mother, father, ground mother, ground father, uncles or aunts), whereas negative family history is defined as those participants who had none family member with glaucoma. There was significant difference in the family history between the two groups $(P=0.000)$; showing that most subjects in POAG group had positive family history of glaucoma while most subjects in nonglaucoma group had negative family history of glaucoma. 
Table 2: Variation of Age and Some Ocular Physiologic Parameters between POAG subjects and Nonglaucoma Subjects

\begin{tabular}{llccc}
\hline Variables & $\begin{array}{c}\text { POAG } \\
\text { Median (IR) }\end{array}$ & $\begin{array}{c}\text { Non-glaucoma } \\
\text { Median (IR) }\end{array}$ & Statistic & P-value \\
& & & & \\
\hline Age (Year) & $60.00(15.00)$ & $60.00(21.00)$ & -0.638 & 0.523 \\
MAP (mmHg) & $98.50(15.00)$ & $95.00(9.50)$ & -1.011 & 0.312 \\
MOPP (mmHg) & $43.00(13.00)$ & $48.00(9.00)$ & -2.622 & $0.009^{*}$ \\
IOP (mmHg) & $21.00(8.00)$ & $16.00(4.75)$ & -4.838 & $0.000^{*}$ \\
C/D Ratio & $0.85(0.10)$ & $0.40(0.10)$ & -8.263 & $0.000^{*}$ \\
TGF- $\beta 1(\mathrm{ng} / \mathrm{ml})$ & $1.40(0.53)$ & $1.20(0.40)$ & -2.051 & $0.040^{*}$ \\
TSP-1 $(\mu \mathrm{g} / \mathrm{ml})$ & $0.23(0.11)$ & $0.21(0.05)$ & -1.035 & 0.301
\end{tabular}

*Statistical significance at $\mathrm{p}<0.05, \mathrm{IR}=$ Interquartile Range, TGF- $\beta 1=$ Transforming Growth Factor-Beta1, TSP1= Thrombospondin-1 
Table 2 shows the Mann-Whitney test result for age and some ocular physiologic parameters between POAG subjects and non-glaucoma subjects. It was shown that the median concentration of TGF- $\beta 1$ (ng/ml) among POAG subjects $(1.40 \mathrm{ng} / \mathrm{ml})$ was higher than that of non-glaucoma subjects $(1.20 \mathrm{ng} / \mathrm{ml})$ which was statistically significant $(P=0.040)$. On the other hand, the median of mean ocular perfusion pressure (MOPP) was lower in POAG subjects $(43.00 \mathrm{mmHg})$ than in nonglaucoma subjects $(48.00 \mathrm{mmHg})$ which was also statistically significant $(P=0.009)$. Besides, median IOP and C/D ratio were higher in POAG subjects $(21,00$ and 0.85 , respectively) than in non-glaucoma (16.00 and 0.4 , respectively). 


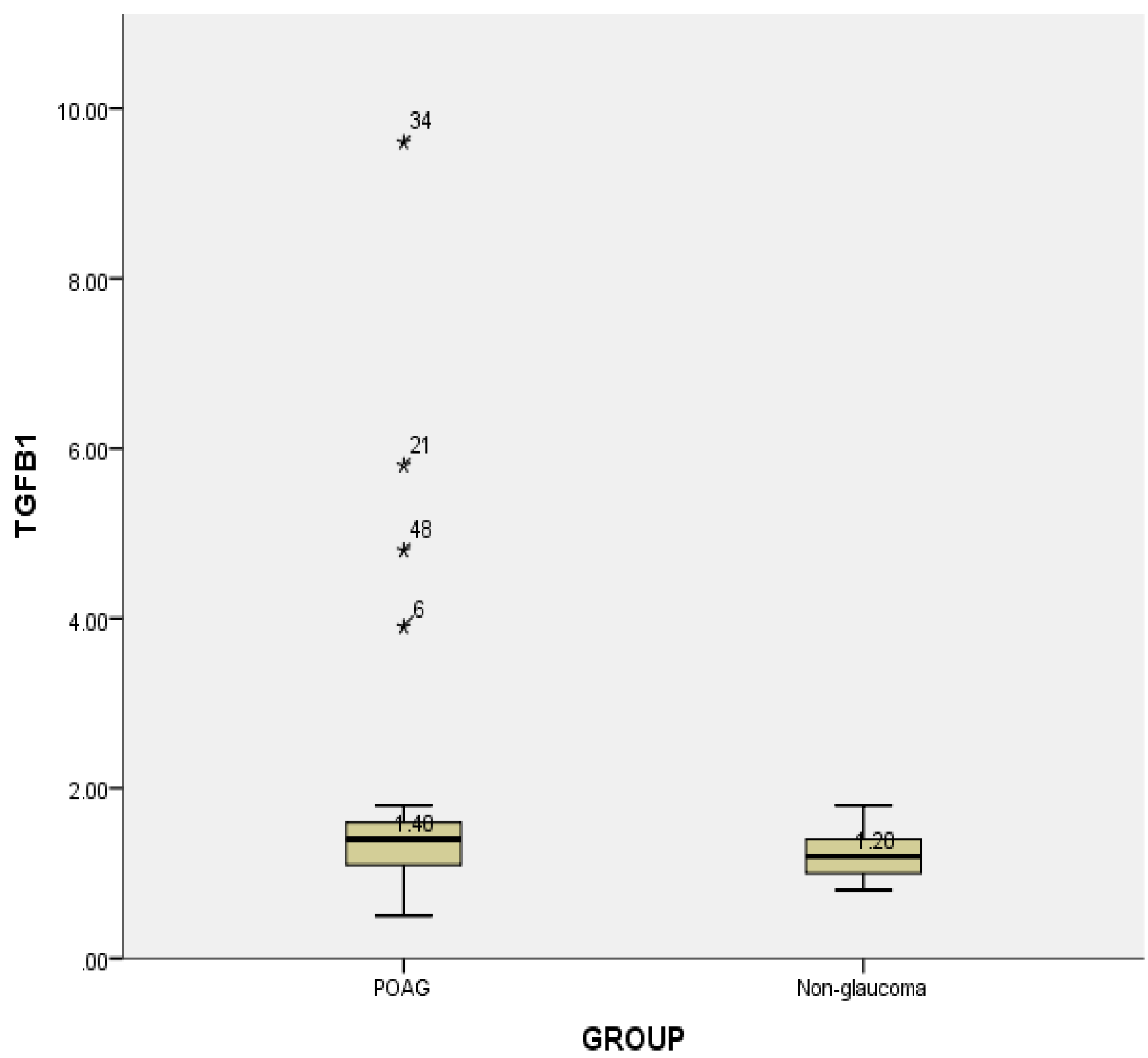

Figure 1: A Plot of Median Interquartile Range of TGF- $\beta 1$ (ng/ml) between POAG and Non-glaucoma Subjects Figure 1 above shows a boxplot of the median interquartile range of TGF- $\beta 1$ (ng/ml) concentration among POAG was from $0.87 \mathrm{ng} / \mathrm{ml}$ to $1.93 \mathrm{ng} / \mathrm{ml}$ which was wider than of the non-glaucoma subjects, being from $0.80 \mathrm{ng} / \mathrm{ml}$ to $1.60 \mathrm{ng} / \mathrm{ml}$. Also, the graph shows some outliers among POAG subjects. 


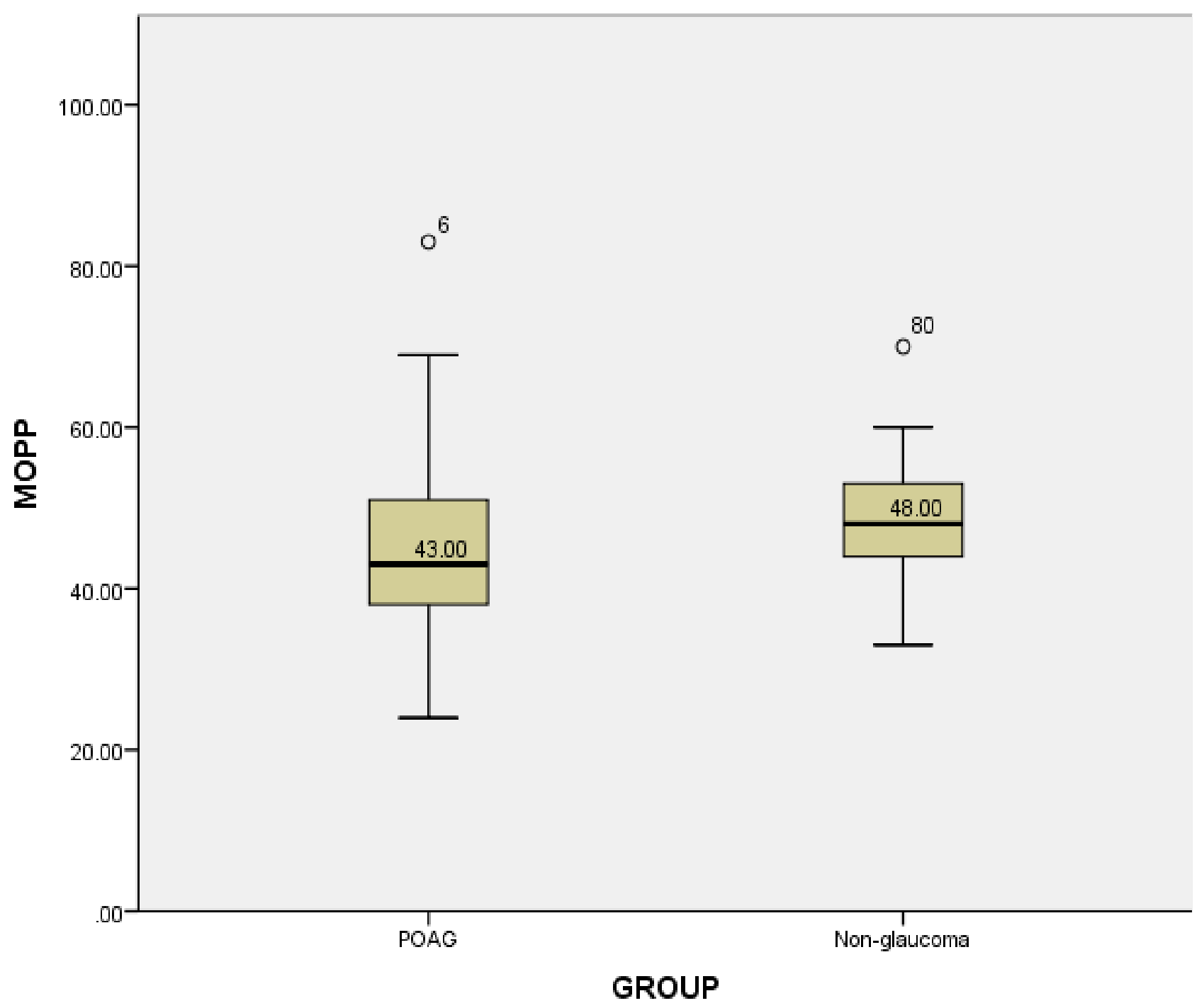

Figure 2: A Plot of Median Interquartile Range of MOPP (mmHg) between POAG and Non-glaucoma Subjects Figure 2 above shows a boxplot of the median interquartile range of MOPP (mmHg) among POAG was from $30.00 \mathrm{mmHg}$ to $53.00 \mathrm{mmHg}$, though median is lower but was wider than of the non-glaucoma subjects; being from $39.00 \mathrm{mmHg}$ to $57.50 \mathrm{mmHg}$. Being wider means that more subjects were within the median of the POAG than non-glaucoma; showing that more of subjects had lower MOPP. Also, the graph shows very few outliers among POAG and non-glaucoma subjects. 
Table 3: Spearman's Correlation between TGF- $\beta 1$ (ng/ml) and Some Ocular Physiologic Parameters among POAG Subjects

\begin{tabular}{lcl}
\hline Variables & $\mathbf{r}_{\mathbf{s}}$ & P-value \\
\hline Age $($ year $)$ & 0.126 & 0.337 \\
MAP $(\mathrm{mmHg})$ & 0.503 & $0.000^{*}$ \\
MOPP $(\mathrm{mmHg})$ & 0.364 & $0.000^{*}$ \\
IOP $(\mathrm{mmHg})$ & 0.002 & 0.990 \\
C/D Ratio & -0.118 & 0.368 \\
TSP-1 $(\mu \mathrm{g} / \mathrm{ml})$ & -0.108 & 0.411
\end{tabular}

* Statistical significance at $\mathrm{p}<0.05$

As shown in table 3 above, the Spearman's correlation test of association between TGF- $\beta 1$ (ng/ml) concentration in the plasma and Age/some ocular physiologic parameters demonstrated a significant association with MAP $(\mathrm{P}=0.000)$ and MOPP $(\mathrm{P}=0.000)$. This shows that as concentration of TGF- $\beta 1$ increased, the MAP and MOPP increased. 
Table 4: Spearman's Correlation between TGF- $\beta 1$ (ng/ml) and Some Ocular Physiologic Parameters among Non-glaucoma Subjects

\begin{tabular}{lcc}
\hline Variables & $\mathbf{r}_{\mathbf{s}}$ & P-value \\
\hline Age $($ year $)$ & 0.353 & $0.033^{*}$ \\
MAP $(\mathrm{mmHg})$ & 0.447 & $0.006^{*}$ \\
MOPP $(\mathrm{mmHg})$ & 0.375 & $0.024^{*}$ \\
IOP $(\mathrm{mmHg})$ & -0.269 & 0.113 \\
C/D Ratio & -0.016 & 0.928 \\
TSP-1 $(\mu \mathrm{g} / \mathrm{ml})$ & -0.016 & 0.928
\end{tabular}

*Statistical significance at $\mathrm{p}<0.05$ 
Spearman's correlation test shown in table 4 above revealed significant association of TGF- $\beta 1$ (ng/ml) concentration in the plasma with Age $(P=0.033), \operatorname{MAP}(P=0.006)$ and MOPP $(P=0.024)$. This shows that as concentration TGF- $\beta 1$ increased, the MAP and MOPP increased, also concentration of TGF- $\beta 1$ increased with advanced age.

\section{DISCUSSION}

This study was done to evaluate relationship between plasma TGF- $\beta 1$ and Primary Open Angle Glaucoma (POAG). Among recruited 96 subjects cohorts comprising of 60 glaucoma subjects as study group and 38 non-glaucoma subjects as control group. Age and BP were measured directly from the subjects while C/D ratio, IOP and visual field results were obtained from their files. Blood samples were obtained from the subjects, then subjected to chemical analysis by ELISA and plasma concentration of TGF- $\beta 1$ and TSP-1 determined, TSP-1 was used to evaluate for platelet's contribution to plasma TGF- $\beta 1$.

The significant association $(P=0.000)$ between the family history and glaucoma as found in this study shows that those with glaucoma had more positive family history than those without glaucoma. This demonstrates that subjects who had their fathers, mothers or siblings with glaucoma had glaucoma than those who had none of those family members with glaucoma. Hence, this study finding of more glaucoma subjects with positive family history provide more evidence in support of positive family history as a risk factor for POAG (Kyari et al., 2015; Omoti \& Edema, 2007; Wolfs et al., 1998).

There was no significant difference $(P=0.523)$ in the median age of subjects between the study group and control groups indicating that there was no difference the age of subjects in both the study and control groups. On the other hand, there was a significant difference in the median $C / D$ ratio $(P=0.000)$ and median IOP $(\mathrm{P}=0.000)$ of subjects between the study and control groups, that demonstrated that both groups were actually independent of each other because those were variables that qualified subjects placement into each group.

This study found a statistical significant $(P=0.040)$ elevation of plasma TGF 1 $(\mathrm{ng} / \mathrm{ml})$ concentration in POAG subjects as compared to non-glaucoma subjects. This finding demonstrates that people with POAG have elevated plasma TGF- $\beta 1$ level. This is in line with other studies which found elevated blood TGF- $\beta 1$ level with trabecular meshwork and lamina cribrosa of the optic nerve head remodeling (structural changes and loss of function) and axonal loss in POAG (Burgoyne, 2011; Kuchtey et al., 2014; Quigley, 2011). Besides, as the period of stress prolongs TGF- $\beta 1$ use for signaling decreases due to abnormal inhibition, remodeling of the microfibrils or microfibrils defects producing 
inactivated latent TGF- $\beta 1$ that are not utilized for signaling (Agapova, 2001; Kuchtey \& Kuchtey, 2014) leading to elevated plasma TGF- $\beta 1$ and then apoptosis RGCs takes lead as reported by Tao et al., (2011). Also, finding of elevated blood TGF- $\beta 1$ in glaucoma individuals in this research is consistent with other research findings; providing additional evidence supporting the microfibrils deficiency hypothesis like in other systemic diseases (Marfan syndrome) and apoptosis hypothesis of glaucoma as documented by Neptune et al., (2003) and Almasiech et al., (2012) respectively.

Likewise, this study found a significant decrease $(P=0.009)$ in median ocular perfusion pressure (MOPP) in POAG subjects than the non-glaucoma subjects which is in line with other studies that reported lower MOPP values in subjects with glaucoma (Agarwal et al., 2009; Tsai, 2009; Budenz et al., 2018). This finding provides more evidence in support of vascular insufficiency theory in the pathogenesis of glaucoma.

Platelet TGF- $\beta 1$ intervening to the plasma TGF- $\beta 1$ was determined by quantifying platelet TGF- $\beta 1$ activator Thrombospondin1 (TSP-1) and it was used as a marker of platelet activation in other studies (McGillicuddy et al., 2006). In this study there was no significant difference $(P=0.301)$ in the level of TSP-1 between glaucoma subjects and controls and with no correlation between TGF $\beta 1$ and TSP1 in both POAG $(P=0.411)$ and non-glaucoma subjects $(P=0.928)$, indicating that there was no significant platelets contribution to plasma TGF 1 which is consistent with previous study finding of no contribution of platelets in citrated plasma (Kropf et al., 1997). However, other study that found otherwise may be because they used acid activated plasma sample; causing degranulation of platelets (Kuchtey et al., 2014). Platelets the main intervening source of plasma TGF- $\beta 1$ which contain high amount of TGF- $\beta 1$ in their a-granules when released during platelet degranulation constitute intervening molecules to the normal plasma TGF- $\beta 1$ variable. This could occur during blood collection, using serum TGF- $\beta 1$, or acid activation of plasma TGF$\beta 1$ but it was significantly minimized in this study by precautions taken. However, TSP-1 is an activator of TGF- $\beta 1$; expression of TGF$\beta 1$ in the trabecular meshwork of glaucoma patients has been shown to be induced by TSP-1 and TSP-1 mRNA expression is induced by stretch activation of cultured lamina cribrosa cells indicating that levels of activated TGF- $\beta 1$ may be increased in POAG leading to elevated blood TSP-1 and activated TGF- $\beta 1$ (FlügelKoch et al., 2004), but not found in this study.

The association between TGF- $\beta 1$ and other ocular physiologic parameters was tested among subjects in both study and Control groups. This study found statistically significant positive association between 
TGF- $\beta 1$ and MAP $(P=0.000), T G F-\beta 1$ and MOPP $(P=0.004)$ in glaucoma subjects. Also, significant positive associations were found between TGF- $\beta 1$ and MAP $(P=0.006)$, TGF- $\beta 1$ and MOPP $(P=0.024)$ in nonglaucoma subjects. Since the same associations of TGF- $\beta 1$ and MAP or MOPP were found in both study and control groups shows that there was no possible vascular contribution to the plasma TGF$\beta 1$. Note that the increased level of TGF- $\beta 1$ upregulates VEGF which has its consequent scaring effect on vascular endothelium and the high plasma level of TGF- $\beta 1$ show that it was not being utilized for signaling (Ferrari et al., 2009; Sundberg \& Rubin, 1996). Then, the consequent scaring effect on endothelium will lead to decreased ocular perfusion. Hence, the positive association seen in plasma may be a reversed of what is happening in RGCs of glaucoma patients.

In addition to associations of TGF- $\beta 1$ and ocular physiologic parameters found among non-glaucoma subjects, this study found an between TGF- $\beta 1$ and age which was statistically significant $(P=0.033)$ and is consistent with other studies that reported about $2 \%$ in middle age and $3.85 \%$ in above $40 y e a r s$ prevalence for glaucoma among old age subjects (Coffey et al., 1993; Klein et al., 1992; Kyari et al., 2015). This finding provides more evidence in support of advanced age as a risk factor for POAG (Bowling, 2016; Omoti \& Edema, 2007) and possibility of elevated plasma
TGF- $\beta 1$ as a risk factor for POAG with advanced age.

Furthermore, other studies found increased TGF- $\beta 1$ with upregulated vascular endothelial growth factor (VEGF), and consequent scarring of the vascular endothelium and angiogenesis (Chang \& Wu, 2009; Liu et al., 2004; Padua \& Massaque, 2009) leading to decreased ocular perfusion among POAG subjects found in this study. Also, this is consistent with the studies which found increased TGF- $\beta 1$ concentration with rise in IOP indicating that mechanical stretch induced optic nerve head astrocytes and trabecula meshwork cells expression of high level of TGF- $\beta 1$ (Kirwan et al., 2004; Kuchtey and Kuchtey, 2014). Likewise, some studies found that stress increased the expression of TGF- $\beta 1$ and VEGF inhibited production of MMP and stimulated tissue inhibitors of MMP leading to scaring of lamina cribrosa of $\mathrm{ONH}$ and TM stenosis (Sundberg \& Rubin, 1996; Chang \& Wu, 2009).

The study by Imanishi et al., (2000) concluded that a number of growth factors and cytokines participate in the regulation of $\mathrm{ONH}$ astrocytes/ganglion cell proliferation and apoptosis as it occurs in the maintenance of corneal transparency. Other study has shown that $\mathrm{N}$ acetylcysteine (NAC) or Nicotinamide adenine dinucleotide phosphate (NADPH) oxidase (e.g NOX1/4) inhibitor may be useful in blocking fibrotic effects of TGF $\beta 1$ 
on fibroblastic cells while keeping its level upregulated, thus acting as antifibroblastic agent (Murphy-Marshman et al., 2017).

\section{CONCLUSION}

The rise in plasma TGF- $\beta 1$ and reduced MOPP values in glaucoma subjects are believed to lead to deterioration of the RGCs as seen in optic nerve head abnormality which eventually leads to optic nerve atrophy in glaucoma irrespective of IOP level. Therefore, TGF- $\beta 1$ level modulation can help prevent RGCs loss and there is possibility of plasma TGF- $\beta 1$ use as a biomarker to monitor the progression of glaucoma disease.

\section{ACKNOWLEDGEMENT}

Special thanks to Dr. Azmat Shah, the Regional Medical Director, Makkah Specialist Eye Hospital, Kano for granting approval to use their patients and patients' information.

My profound appreciation to Dr. Sadia Hassan, consultant Ophthalmologist, Aminu Kano Teaching Hospital, Kano and visiting consultant, Makkah Specialist Eye Hospital, Kano for his assistance. Also, Medical Laboratory Scientists Bashir Abdullahi and Suleiman Jibrin Dadinkowa for their direction and assistance on blood sample collection, processing and chemical analysis.

\section{REFERENCES}

Agapova, O.A., Ricard, C.S., SalvadorSilva, M., and Hernandez, M.R. (2001). Expression of matrix metalloproteinases and tissue inhibitors of metalloproteinases in human optic nerve head astrocytes. Glia; 33:205-16.

Agarwal, R., Gupta, S. K., Agarwal, P., Saxena, R., and Agarwal, S. S. (2009). Current concepts in the pathophysiology of glaucoma. Indian Journal of Ophthalmology, 54(4): 257-266.

Almasieh, M., Wilson, A.M., Morquette, B., Cueva Vargas, J.L., and Di Polo, A. (2012). The molecular basis of retinal ganglion cell death in glaucoma (Review). Progress in Retinal Eye Research, 31 (2):152-181.

Aung, T., Okada, K., Poinoosawmy, D., Membrey, L., Brice, G., Child, A.H., Bhattacharya, S.S., Lehmann, O.J., Garway-Health, D.F., and Hitchings, R.A. (2003). The phenotype of normal tension glaucoma patients with and without OPAl polymorphisms. British Journal of Ophthalmology, 87:149-52.

Bonomi, L., Marchini, G., Marraffa, M., Bernardi, P., Moorbio, R., and Varotto, A. (2000). Vascular risk factors for primary open angle glaucoma: the EgnaNeumarkt Study. Ophthalmology, 107(7):1287-1293. 
Bowling, B. (2016). Kanski Clinical Ophthalmology: Systemic Approach 8th ed. Elservier Saunders: New South Wales. Pg 350-351.

Buhrmann, R.R., Quigley, H.A., Barron, Y., West, S.K., Oliva, M.S., and Mmbaga, B.B.O. (2000). Prevalence of glaucoma in a rural East African population. Investigative Ophthalmology and Visual Science, 41:4048.

Budenz, D.L., Piltz-Seymour, J.R, Singh, K., Topouzis, F. and Varma, R. (2018). The "New" Pressure for Glaucoma Specialists: Ocular Perfusion Arrives. American Academy of Ophthalmology; 12: 1-4.

Burgoyne, C.F. (2011). A Biomechanical Paradigm for Axonal Insult within the Optic Nerve Head. Experimental Eye Research, 93(2): 120-132.

Chang, Y. and Wu, X.Y. (2009). The role of C-Jun $\mathrm{N}$-terminal Kinases $1 / 2$ in transforming growth induced expression of connective tissue growth factor and scar formation in the cornea. Journal of International Medical Research, 37(3):727- 36.

Chauhan, B.C. (1995). The relationship between intraocular pressure and visual field progression in glaucoma. In: S.M. Drance (ed.), Update to glaucoma, blood flow and drug treatment. Amsterdam: Kugler. pp.1-6.

Coffey, M., Reidy, A., Wormald, R.P.L., Xian, W.X., Wright, L., and Courtney, P. (1993). Prevalence of glaucoma in the West of Ireland. British Journal of Ophthalmology, 77:17-21.

Coleman, A.L. (1999). Glaucoma. Lancet, 354:1803-10.

Cordeiro, M.F. (2002). Beyond mitomycin: TGF-Beta and wound healing. Progress in Retinal Eye Research, 21 (1):75-89.

Declaration of Helsinki (1964). Recommendations guiding doctors in clinical research. Adopted by the 18th World Medical Assembly, Helsinki, Finland, June, 1964.

Derynck, R. and Feng, X.H. (1997). TGFbeta receptor signaling. Biochimica Biophysica Acta., 1333(2):F105-50.

Derynck, R., and Zhang, Y.E. (2003). Smad-dependent and Smad--independent pathways in TGF-beta family signaling. Nature, 425(6958):577-84.

Ferrari, G., Cook, B.D., Terushkin, V., Pintucci, G., and Mignatti, P. (2009). Transforming growth factor-betal induces angiogenesis through vascular endothelial growth factor (VEGF) mediated apoptosis. 
Journal of Cellular Physiology, 219(2):44958.

Flammer, J., and Mozaffarieh, M. (2007). What is the present pathogenetic concept of glaucomatous optic neuropathy? Survey of Ophthalmology 52(Suppl):S16273.

Flügel-Koch, C., Ohlmann, A., Fuchshofer, R., Welge-Lüssen, U., Ernst R. \& Tamm, E.R. (2004). Thrombospondin-1 in the trabecular meshwork: localization in normal and glaucomatous eyes, and induction by TGFBland dexamethasone in vitro. Experimental Eye Research, 79 (5): 649-663.

Gass, A., Flammer, J., Linder, L., Romerio, S.C., Gasser, P., and Haefeli, W.E. (1997). Inverse correlation between endothelin-1induced peripheral microvascular vasoconstriction and blood pressure in glaucoma patients. Graefe's Archive for Clinical and Experimental Ophthalmology, 235:634-8.

Guzman, G., Javitt, J.C., and Glick, H. (1992). Glaucoma in the United States population: the economic burden of illness. Investigative Ophthalmology Visual Science, 33:S759.

Hendrick, K.H., Van den Enden, A., Rasker, M.T., and Hong, P.F. (1994). Cumulative incidence of patients with disc hemorrhages in glaucoma and the effect of therapy. Ophthalmology, 101:1165-72.

Henson, D.B., Chaundry, S., Artes, P.H., Faragher, E.B., and Ansons, A. (2000). Response variability in the visual field: comparison of optic neuritis, glaucoma, ocular hypertension, and normal eyes. Investigative Ophthalmology and Visual Science, 41:417-421.

Houghton, P.E., Keefer, K.A., and Krummel T.M. (1995). The Role of transforming growth factor-beta in the conversion from "Scarless" healing to healing with scar formation. Wound Repair Regen, 3(2):22936.

Huang, T., Schor, S.L., \& Hinck, A.P. (2014). Biological Activity Differences between TGF- $\beta 1$ and TGF- $\beta 3$ Correlate with Differences in the Rigidity and Arrangement of Their Component Monomers. Biochemistry, 53(36): 5737-5749. Kanski, J.J. (2016). Clinical Ophthalmology: The glaucoma, 8th ed. Oxford, UK: Butterwort-Heineman. pp. 366-367.

Kerrigan-Baumrind, L.A., Quigley, H.A., Pease, M.E., Kerrigan, D.F., and Mitchell, R.S. (2000). Number of ganglion cells in glaucoma eyes compared with threshold visual field tests in the same persons. Investigative Ophthalmology and Visual Science, 41: 741-748. 
Khurana, A.K. (2007). Comprehensive Ophthalmology: Glaucoma, 4th ed. New Delhi: New age international Itd., pp. 204241.

Kingman, S. (2004). Glaucoma now second leading cause of blindness. Bulletin of World Health Organization, 82(11):811-890.

Kirwan, R.P., Crean, J.K., Fenerty, C.H., Clark, A.F., and O'Brien, C.J. (2004). Effect of cyclical mechanical stretch and exogenous transforming growth factorbetal on matrix metalloproteinase-2 activity in lamina cribrosa cells from the human optic nerve head. Journal of Glaucoma, 13(4):327-334.

Klien, B.E.K., Klien, R., Sponsel, W.E., Franke, T., Cantor, L.B., Martone, J., and Menage, M.J. (1992). Prevalence of glaucoma: the Beaver Dam eye study. Ophthalmology, 99:1499-1504.

Kropf, J., Schurek, J.O., Wollner, A., and Gressner, A.M. (1997). Immunological measurement of transforming growth factor-beta 1 (TGF- $\beta 1$ ) in blood; assay development and comparison. Clinical Chemistry, 43(10): 1965-1974.

Kuchtey, J. and Kuchtey, R.W. (2014). The Microfibril Hypothesis of Glaucoma: Implications for Treatment of Elevated Intraocular Pressure. Journal of Ocular Pharmacology and Therapeutics $30(2,3)$.
Kyari, F., Abdull, M.M, Bastawrous, A., Gilbert, C.E. and Faal, H. (2013). Epidemiology of Glaucoma in Sub-Saharan Africa: Prevalence, Incidence and Risk Factors. Middle East African Journal of Ophthalmology; 20(2): 111-125.

Kyari, F., Entekume, G., Rabiu, M., Spry, P., Wormaild, R., Nolan,W., Murthy, G.V. and Gilbert, C.E., (2015). A Population-based survey of the prevalence and types of glaucoma in Nigeria: results from the Nigeria National Blindness and Visual Impairment survey. British Medical College of Ophthalmology; 15:176.

Liu, W., Wang, D.R., and Cao, Y.L. (2004). TGF-beta: a fibrotic factor in wound scaring and potential target for antiscaring gene therapy. Current Gene Therapy, 4(1):123-36.

McGillicuddy, F.C., O'Toole, D., Hickey, J.A., Gallagher, W.M., Dawson, K.A., and Keenan, A.K. (2006). TGF- $\beta 1$-induced thrombospondin-1 expression through the p38 MAPK pathway is abolished by fluvastatin in human coronary artery smooth muscle cells. Vascular Pharmacology, 44(6): 469-475.

Memarzadeh, F., Ying-Lai, M., Chung, J., Aze, S.P., and Varma, R. (2010). Los Angeles Latino Eye Study Group. Blood pressure, perfusion pressure, and openangle glaucoma: the Los Angeles Latino 
Eye Study. Investigative Ophthalmology and Visual Science, 51(6):2872-2877.

Murphy-Marshman H, Quensel K, Shi-wen X, Barnfield R, Kelly J, Peidl A, Stratton, R.J., and Leask, A. (2017). Antioxidants and NOX1/NOX4 inhibition blocks TGFB1induced CCN2 and a-SMA expression in dermal and gingival fibroblasts. PLOS ONE 12(10):e0186740.

Neptune, E.R., Frischmeyer, P.A., Arking, D.E., Myers, L., Bunton, T.E., Gayraud, B., Ramirez,

F., Sakai, L.Y., and Dietz, H.C. (2003). Dysregulation of TGF-beta activation contributes to pathogenesis in Marfan syndrome. Nature of Genetics, 33(3):40711.

Nomura, H., Shimokata, H., Ando, F., Miyake, Y., and Kuzuya, F. (1999). Agerelated changes in intraocular pressure in a large Japanese population: A crosssectional and longitudinal study. Ophthalmology, 106:2016-22.

Omoti, A.E and Edema, O.T. (2007). A reviiew of the risk facttors in primary open angle glaucoma. Nigerian Journal Clinical Practice; 10(1):79-82.

Padua, D., and Massaque, J. (2009). Roles of TGF-Beta in metastasis. Cellular Research, 19(1):89-102.
Pang, C.P., Leung, Y.F., Fan, B., Baum, L., Tong, W.C., Lee, W.S., Chua, J.K.H., Fan, D.S.P. and Lam, D.S.C. (2002). TIGR/MYOC Gene Sequence Alterations in Individuals with and without Primary Open-Angle Glaucoma. Investigative Ophthalmology and Visual Science, 43:3231-35.

Quigley, H.A. (2011). Glaucoma. Lancet. 377(9774):1367-77.

Quigley, H. A. and Broman, A. T. (2006). The number of people with glaucoma worldwide in 2010 and 2020. British Journal of Ophthalmology, 90(3): 262-267.

Quigley, H.A., West, S.K., Rodriguez, J., Munoz, B., Klein, R., and Snyder, R. (2001). The prevalence of glaucoma in a population-based study of Hispanic subjects: Proyecto VER. Archive of Ophthalmology, 119(12):1819-1826.

Robert N. W. (2008). Glaucoma Worldwide: A Growing Concern. Glaucoma Research Foundation. Retrieved from https://www.glaucoma.org/qa/glaucoma-worldwide.php

Roberts, A.B, Soporn, M.B, and Assoian, R.K. (1986). Transforming growth factor Beta, rapid induction of flowsis and argiogenesis invitro and stimulation of collagen formation invitro. Proceedings of National Academy of Science, USA, 83: 4167-4171. 
Shaikh, Y., YU, F., and Coleman, A.L. (2014). Burden of undetected and untreated glaucoma in the United States. American Journal of Ophthalmology, 158(6):11211129.e1.

Sigal, I.A., Flanagan, J.G., Tertinegg, I., and Ethier, C.R. (2009). Modeling individualspecific human optic nerve head biomechanics. Part I: IOP-induced deformations and influence of geometry. Biomechanical Model Mechanobiology, 8(2):85-98.

Sommer, A., Tielsch, J.M., Katz, J., Quigley, H.A., Gottsch, J.D., Javitt, J.C., Martone, J.F., Royall, R.M., Witt, K.A., and Ezrine, S. (1991). Racial differences in the causespecific prevalence of blindness in east Baltimore. New England Journal Medicine, 325(20):1412-7.

Sundberg, C.R. and Rubin, K. (1996). Stimulation of TGF-B intergrin on fibroblasts induced PDGF independent tryosine phosphorylation of PDGF B- receptor. Journal of Cellular Biology, 132:741-32.

Tandon, A., Torey, J.C, Shama, A., Gupta, R. and Mohan, R.R. (2010). Role of transforming growth factor Beta in corneal function biology and pathology. Current Molecular Medicine, 10:565-578.
Tao, Y., Gao, D., and YU, M. (2011). TGF$\beta 1$ in retinal ganglion cells in rats with chronic ocular hypertension: its expression and anti--apoptotic effect. International Journal of Ophthalmology, 4(4): 396-401.

Tham, Y., Li, X., Wong, T.Y, Quigley, H.A, Aung, T., and Cheng, C. (2014). Global Prevalence of Glaucoma and Projections of Glaucoma Burden through 2040: A Systematic Review and Meta-Analysis. American Academy of Ophthalmology, 121:2081-2090.

Thylefors, B. and Negrel A.D. (1994). The global impact of glaucoma. Bulletin of World Health Organization, 72(3):323-326.

Tielsch, J.M., Katz, J., Singh, K., Quigley, H.A., Gottsch, J.D., and Javitt, J. (1991). A population-based evaluation of glaucoma screening: The Baltimore Eye Survey. American Journal of Epidemiology, 134:1 102-10.

Tsai, J.C. (2009). Should We Measure (and Treat) Ocular Perfusion Pressure in Glaucoma Patients? Glaucoma Today; 12: $1-2$.

Van Keer, K., Breda, J.B., Pinto, L.A., Stalmans, I., Evelien Vandewalle, E. (2016). Estimating Mean Ocular Perfusion Pressure Using Mean Arterial Pressure and Intraocular Pressure. Investigative Ophthalmology \& Visual Science; 57: 2260. 
Wakefield, L.M., Letterio, J.J., Chen, T., Danielpour, D., Allison, R.S., Denicoff, A.M., Cowan, K.H., O'Shaughnessy, J.A. and Pai, L.H. (1995). Transforming growth factorbetal circulates in normal human plasma and is unchanged in advanced metastatic breast cancer. Clinical Cancer Research, 1:129-136.

Wang, C.Y., Chen, L.L., Kuo, P.Y., Chang, J.L., Wang, Y.J., and Hung, S.C. (2010). Apoptosis in chondrogenesis of human mesenchymal stem cells: effect of serum and medium supplements. Apoptosis, 15(4):439-49.

Wipff, P.J., and Hinz, B. (2008). Integrins and the activation of latent transformation growth factor beta 1- an intimate relationship. European Journal of Cell Biology, 87(8-9): Eol- 15.

Wolfs, R.C.W., Klaver, C.C.W., Ramrattan, R.S., Van Duijn, C.M., Hofman, A., and De Jong, P.T.V.M. (1998). Genetic risk of primary open glaucoma. Archive of Ophthalmology, 116:1640-45.

World Medical Association (2013). World Medical Association (WMA) Declaration of Helsinki - Ethical Principles for Medical Research Involving Human Subjects. 64th WMA General Assembly, Fortaleza, Brazil, October, 2013. 